\title{
Evolución de las temperaturas medias recientes en Navarra
}

\author{
Javier M. Pejenaute GoñI *
}

\section{RESUMEN}

Se trata del análisis estadístico de las temperaturas medias en las tres comarcas navarras más representativas en el período 1941 97, para ver hasta qué punto se está dando un incremento térmico en los últimos años. Se estudia la homogeneidad, centralidad, dispersión y variabilidad, frecuencia y probabilidad, y organización y aleatoriedad de tres series cronológicas. Finalmente se analizan los períodos distintos que se dan dentro de las temperaturas medias, el grado de correlación y la tendencia futura anual y estacional mediante el estudio del coeficiente de correlación y la recta de regresión lineal.

\section{ABSTRACT}

This study shows the statistical analysis of the average temperatures in the three most representative Navarrese regions between 1941 and 1997 to observe to what extent there has been a thermic rise in recent years. Homogeneity, centrality, dispersion and variability, frequency and probability and organization and randomness are studied in three chronological series. Finally, the different periods among the average temperatures, the degree of correlation and the future annual and seasonal tendency are analyzed through the study of the correlation coefficient and the linear regression line.

- Prof./tutor Geografía UNED-Pamplona). 


\section{INTRODUCCIÓN}

Es creencia general dentro de la comunidad científica que en los últimos años se está produciendo un aumento de las temperaturas en el mundo y en la Península. Incremento térmico que está en función del aumento de la proporción de anhidrido carbónico en la atmósfera. Se parte, así pues, de la hipótesis inicial de búsqueda de una tendencia creciente de las temperaturas en Navarra. Por otra parte, la idea que tiene la gente de nuestra tierra, muy influida por los medios de difusión y la literatura sensacionalista, es que el calor cada vez es mayor y las temperaturas aumentan.

Se pretende estudiar estadísticamente las series cronológicas de las temperaturas medias en las tres comarcas navarras más representativas en el periodo 1941-97. Con ello se intenta ver su evolución; observar, con todas las reservas, si se está dando el incremento de las temperaturas y en qué medida; y analizar los períodos distintos que se pueden distinguir, en un intento de buscar una posible autocorrelación, mediante el coeficiente de correlación y la recta de regresión lineal.

Al prestar atención a la representación gráfica de las series de temperaturas se observa, en una primera aproximación, la presencia de tres períodos diferentes. El primero, caracterizado por los valores térmicos altos, normalmente por encima de la temperatura media del período total, que dura hasta los años sesenta, con alguna diferencia según los distintos observatorios. A continuación le sigue un segundo periodo con temperaturas medias suaves, por debajo de la media, que iría creciendo moderadamente desde los sesenta hasta los ochenta. Y finalmente, el último, con temperaturas altas y ascendentes. Por ello, una vez visualizadas las gráficas de temperaturas medias anuales se han fragmentado las series, para su estudio, en cuatro períodos: años 1941 a 1997, es decir el total de años; 1941 a 1970, la primera mitad de la serie; 1971 a 1997, la segunda mitad; y 1981 a 1997, los últimos años. Estos dos últimos representarían los años en que. según creencia general, estarían aumentando las temperaturas.

Somos conscientes de que para llegar a la estimación de estas características hay que someter la información estadística a una serie de pruebas. Sabemos las dificultades y los riesgos que esto entraña, pues no siempre la relación es clara, y aun siendo así, habrá que pensar si se puede mantener la tendencia o habrá fluctuaciones. Nos planteamos hasta qué punto la estadística descriptiva puede ser interpretativa en este caso. 


\section{LONGITUD Y HOMOGENEIDAD DE LAS SERIES}

Se ha elegido la temperatura media por ser el dato térmico más representativo, porque tiene en cuenta calor del dia y el frío de la noche. Se ha considerado una muestra de cincuenta y siete años, desde el año 1941 hasta el año 1997 para los observatorios de Santesteban (Valles Cantábricos), Pamplona (Cuenca de Pamplona) y Carcastillo (Ribera de Navarra). Estos tres observatorios, estratégicamente situados, representan los tres climas más destacados de Navarra: atlántico u oceánico (Santesteban), transición oceánico-mediterráneo (Pamplona) y mediterráneo continental (Carcastillo).

Estos observatorios son fiables, han funcionado bien y han tenido pocos cambios en su ubicación. La primera limitación importante viene dada por la escasa longitud de las series, con las que es difícil observar cambios importantes. No se ha querido ampliar las series para evitar los años de la Guerra Civil y los anteriores, dado que el grado de fiabilidad se desconoce y las lagunas aumentan. Cincuenta y siete años es una serie apreciable de temperaturas medias, pero insuficiente. Sin duda, uno de los problemas con que se tropieza en climatología es evaluar el posible incremento térmico con series cortas de datos. Por otra parte, es difícil poder contar con observatorios que no hayan tenido cambios en su ubicación durante todo el período considerado ${ }^{1}$.

La homogeneidad indica el grado de distribución de las temperaturas medias dentro de la serie temporal. Para comprobar el grado de homogeneidad se han aplicado el test de las rachas y el de Helmert o de las permanencias. Con respecto al primero en Santesteban y en Pamplona se

\footnotetext{
1 De los tres observatorios seleccionados solamente Carcastillo-la Oliva ha estado emplazado siempre en el mismo lugar a $42^{\circ} 22^{\prime} \mathrm{N}$ y $2^{\circ} 13^{\prime} \mathrm{E}$ y a una altitud de $340 \mathrm{~m}$.

El observatorio de Santesteban se encontraba situado hasta enero de 1984 a $43^{\circ} 07^{\prime} 46^{\prime \prime} \mathrm{N}$ y $1^{\circ} 39^{\prime} 50^{\prime \prime}$ y a una altitud de $131 \mathrm{~m}$. El año 1984 experimentó una variación dentro del pueblo que no debe ser muy significativa, por la diferencia entre el lugar anterior y éste. Se encuentra a $43^{\circ} 08^{\prime} \mathrm{N}$ y $2^{\circ} 02^{\prime} \mathrm{E}$ y una altitud de $122 \mathrm{~m}$.

El observatorio de Pamplona ha cambiado dos veces de emplazamiento. Desde los inicios de la serie hasta el 21 de agosto de 1953 estuvo situado en la terraza del Instituto Ximénez de Rada, en la Plaza de la Cruz de Pamplona, con unas coordenadas de $42^{\circ} 48^{\prime} 42^{\prime \prime} \mathrm{N}$ y $1^{\circ} 38^{\prime} 33^{\prime \prime} \mathrm{W}$ y a una altitud de $475 \mathrm{~m}$. Desde esta fecha hasta el 30 de septiembre de 1994 se emplazó en el torreón noroeste del edificio de la Escuela de Empresariales, en la calle Navarrería 39, Casco Viejo, con unas coordenadas de $42^{\circ} 49^{\prime} 10^{\prime \prime} \mathrm{N}$ y $1^{\circ} 38^{\prime} 36^{\prime \prime} \mathrm{W}$ y una altitud de $461 \mathrm{~m}$. A partir de octubre de 1994 se sitúa definitivamente junto al Parque de la Media Luna con unas coordenadas de $42^{\circ} 49^{\prime} 01^{\prime \prime} \mathrm{N}$ y $1^{\circ} 38^{\prime} 16^{\prime \prime} \mathrm{W}$. Dada la altitud bastante parecida y su ubicación dentro de la ciudad, en los tres casos dentro del casco urbano, no se cree que sus variaciones sean grandes. Además, la mayor parte de la serie discurre en su segunda ubicación.
} 
han anotado 23 rachas durante toda la serie, dato que se encuentra justamente dentro de los umbrales permitidos para los niveles de probabilidad del $2,5 \%$ y $97,5 \%$, para un período de sesenta años, que son 22 y 39 . En Carcastillo, por el contrario, sólo se han observado 19 rachas o cambios que no llegan, por poco, al intervalo mínimo para esa probabilidad.

No superan, en cambio, el test de Helmert o de las permanencias. La diferencia entre permanencias y cambios (Santesteban 14, Pamplona 18, Carcastillo 18) es superior a la raíz cuadrada del número de datos de la serie menos uno. En Santesteban esto es debido, sobre todo, a los períodos 1958-67, que fueron años cálidos seguidos, situados por encima de la temperatura media, y al período 1968-80, que fueron años fríos, situados por debajo de la temperatura media. Han sido muy fluctuantes los años 1943-47, 1950-58 y los últimos de las series,

En Pamplona la no superación se debe, sobre todo, a los 18 años seguidos, por debajo de la temperatura media, que tuvieron lugar en los años 1963-81 y a las permanencias por encima de la temperatura media de los años 1945-49 y 1987-91. Los años 1949-63, 1981-87 y los últimos, fueron de cambios. En Carcastillo sucede lo mismo: el período 1965-80, con 15 permanencias por debajo de la temperatura media, impide la superación de la prueba. Los períodos $1942-50$ y 85-91 anotaron bastantes permanencias al situarse por encima de la temperatura media y los años 1950$65,80-85$ y los últimos, fueron de cambios.

Por lo tanto, cabe pensar que el elevado número de permanencias, no es debido al cambio en los instrumentos de medida o a la distinta ubicación de los observatorios, sino a las variaciones climáticas naturales: ciclos de altas temperaturas al comienzo, bajas temperaturas intermedias y altas al final.

\section{CENTRALIDAD}

Uno de los primeros pasos al analizar las series de temperaturas medias anuales en los tres observatorios ha sido determinar su valor central mediante el cálculo de la media y la mediana en los diferentes períodos seleccionados.

La temperatura media anual en Santesteban para el período 1941-97 es $13,87^{\circ}$. Desciende ligeramente en los años 1971-97 con un resultado de $13,63^{\circ}$. Aumenta considerablemente en el período intermedio 1941-70 donde se concentran años muy cálidos. En el período más reciente de 1981-97 la temperatura media aumenta con respecto a los años 1971-97 $\left(13,95^{\circ}\right)$. 
En el observatorio de Pamplona la temperatura media anual para el período más largo de la serie, $1941-97$, es $12,52^{\circ}$. Se mantiene en el período intermedio $1941-70$ con un resultado de $12,5^{\circ}$. No presenta variación en el período 1971-97 con un resultado de $12,55^{\circ}$. En el período más reciente de 1981-97 la temperatura media alcanza su más alto valor con $12,79^{\circ}$.

La temperatura media anual en Carcastillo- la Oliva para el período 1941-97 es $13,25^{\circ}$. Se mantiene en los años 1971-97 con un resultado de $13,28^{\circ}$ y en el período intermedio $1941-70$ con $13,22^{\circ}$. En el más reciente considerado, 1981-97, la temperatura media alcanza su valor más alto con $13,67^{\circ}$.

También se va a analizar la mediana, o sea el valor que divide en dos conjuntos a las series de temperaturas, una vez ordenados. En el observatorio de Santesteban la mediana es de $13,71^{\circ}$ para el total de la serie. Desciende ligeramente a $13,61^{\circ}$ en el período 1971-97 y aumenta considerablemente a $14,08^{\circ}$ en los primeros treinta años, período 1941-70. Hay una aumento en los últimos años, al igual que sucedía con las temperaturas medias, en el período 1981-97, en que se sitúa en los 13,79 .

En el observatorio de Pamplona, prototipo de clima de transición oceánico-mediterráneo, la mediana es $12,41^{\circ}$ para el total de la serie. Repite el mismo valor en los períodos 1971-97 y 1941-70 y hay una aumento, al igual que sucedía con las temperaturas medias, en el período 1981-97, en que se sitúa en $12,7^{\circ}$.

En Carcastillo, la mediana es de $13,2^{\circ}$ para el total de la serie y para el período 1971-97, y aumenta en los años 1941-70, situándose en 13,59. Hay un ascenso en los últimos años, al igual que sucedía con las temperaturas medias, en el período 1981-97, en que se sitúa en $13,77^{\circ}$.

En los tres observatorios se da proximidad o coincidencia entre la media y la mediana, por lo que la media aritmética representa también la centralidad. En el período 1981-97 hay un aumento importante de la temperatura media y de la mediana con respecto al total de la serie y a los otros períodos en Pamplona y Carcastillo, y más moderado en Santesteban.

\section{DISPERSIÓN Y VARIABILIDAD}

La dispersión es la distribución de las temperaturas medias de cada año teniendo en cuenta el conjunto de ellos o su relación con respecto al valor central. Se ha calculado primeramente el recorrido o rango; después 
los quintiles, que permiten dividir la serie en cinco tipos de años, denominados muy fríos, fríos, templados, cálidos y muy cálidos; a continuación la desviación estándar; y, finalmente, el coeficiente de variación. Estos datos señalan la variabilidad de las temperaturas medias.

En Santesteban, para el período comprendido entre 1941-97 la temperatura media más alta fue de $15,9^{\circ}$ (año 1961) y la más baja de $12,5^{\circ}$ (año 1954), por lo que el recorrido o rango es de $3,4^{\circ}$.

Del estudio de los quintiles se ve que en el período 1941-97 se han contabilizado 13 años muy fríos, 11 fríos, 13 templados, 9 cálidos y 11 muy cálidos. En los años 41-70 se han observado 4 años muy fríos, 6 fríos, 7 templados, 3 cálidos y 10 muy cálidos. En el período $71-97$ se han visto 9 años muy fríos, 5 fríos, 6 templados, 6 cálidos y 1 muy cálido. En los años 81-97, se da 1 año muy frío, 3 fríos, 6 templados, 6 cálidos y 1 muy cálido? .

Estos resultados permiten apuntar unas primeras apreciaciones. Los años muy cálidos no tienen lugar, sólo, en los últimos años, sino en el período comprendido entre los años 1941 y 70 . A partir de 1981 se nota una casi total ausencia de años muy fríos, una escasa presencia de fríos y una frecuencia importante de años cálidos. Y finalmente desde el año 91 hasta la actualidad, es decir en los últimos siete años, el equilibrio es la norma, con 3 años fríos, 1 templado, 2 cálidos y 1 muy cálido. Por lo tanto, el aumento de años cálidos visible a partir de los ochenta no tendría una continuación igual de alta en los noventa.

La desviación estándar anual en Santesteban para el total de la serie, años 1941-97, es 0,71. Para el período 1971-97 la anual es 0,57, o sea inferior con respecto a la del total de la serie. Si se observa el período 1941 . 70 la desviación estándar anual de 0,76 es elevada y vuelve a parecerse a la de la serie total. Finalmente para los años 1981-97 la desviación estándar anual es de 0,44.

O sea, existe una diferencia entre los años 71-97 y 81-97 por una parte, con una desviación estándar inferior, y los años 1941-97 y 41-70 por otra, con

\footnotetext{
Se han calculado los quintiles en los tres observatorios. En Santesteban, los años comprendidos entre $12,5^{\circ}$ y $13,3^{\circ}$ de temperatura media se pueden considerar muy fríos; los situados entre $13,4^{\circ}$ y $13,6^{\circ}$ son fríos; templados los que están entre $13,7^{\circ}$ y $14,1^{\circ}$; cálidos los que entran dentro del grupo $14,2^{\circ}$ y $14,5^{\circ}$; y muy cálidos los comprendidos entre $14,5^{\circ}$ y $15,9^{\circ}$. En Pamplona los años comprendidos entre $11,1^{\circ}$ y $12^{\circ}$ se consideran muy fríos; los situados entre $12,1^{\circ}$ y $12,3^{\circ}$ son fríos; templados los que están entre $12,4^{\circ}$ y $12,6^{\circ}$; cálidos los que entran dentro del grupo $12,7^{\circ}$ y $13,2^{\circ}$; y muy cálidos los comprendidos entre $13,3^{\circ}$ y $13,9^{\circ}$. En Carcastillo, los años comprendidos entre $11,8^{\circ}$ y $12,7^{\circ}$ se consideran muy fríos; los situados entre $12,8^{\circ}$ y $13^{\circ}$ son fríos; templados los que están entre $13,1^{\circ}$ y $13,4^{\circ}$; cálidos los que entran dentro del grupo $13,5^{\circ}$ y $13,8^{\circ}$; y muy cálidos los comprendidos entre $13,9^{\circ}$ y $14,8^{\circ}$.
} 
una desviación estándar superior. Desde el comienzo de las series hasta el año setenta las variaciones, sin duda, fueron más acusadas. En general, los meses de invierno tienen valores más altos y los de verano más bajos.

El coeficiente de variación en Santesteban resulta más alto en los períodos 1941-97 y 1941-70 (5,14 y 5,41 respectivamente) que en los 197197 y $1981-97(4,16$ y 3,13$)$, resultados parecidos a los obtenidos en otros estudios (Raso, 1997). Los meses de invierno son los más variables en todos los períodos y los de verano los que menos variabilidad presentan. De los meses de primavera el más variable es marzo y de los de otoño, noviembre. Destaca la muy alta variación de febrero en los períodos 1941 97 y $1941-70$

En definitiva se puede afirmar que durante el período 1941-70 se registró una mayor variabilidad. A partir de los años ochenta la variabilidad global es inferior. En estos últimos años los meses presentan una fuerte variación, sobre todo enero. A los meses de invierno les sigue por su alta variabilidad marzo, noviembre y abril.

En Pamplona, para el período comprendido entre 1941-97 la temperatura media más alta fue de $13,9^{\circ}$ (año 1947) y la más baja de $11,1^{\circ}$ (año 1941 ), por lo que el recorrido o rango es de $2,8^{\circ}$, inferior al del observatorio de Santesteban.

Según los datos de los quintiles, en el período 1941-97 se han contabilizado 15 años muy fríos, 10 fríos, 10 templados, 12 cálidos y 10 muy cálidos. En los años 41-70 se han observado 11 años muy fríos, 3 fríos, 5 templados, 7 cálidos y 4 muy cálidos. En el período 71-97 se han visto 4 años muy fríos, 7 fríos, 5 templados, 5 cálidos y 6 muy cálidos. En los años 81-97 se han observado 1 año muy frío, 3 fríos, 2 templados, 5 cálidos y 6 muy cálidos.

Estos resultados obtenidos en Pamplona permiten apuntar unas primeras conclusiones. De los diez años muy cálidos que registra la serie, seis han tenido lugar a partir del año 1981, tres de los cuales pertenecen a los años noventa. Casi la mitad de los años cálidos anotados, o sea cinco de once, se dan a partir de 1981, y de ellos sólo uno en los años noventa. En el extremo contrario se observa que sólo tiene lugar un año muy frío desde 1981 de los quince registrados en toda la serie y tres fríos de los diez que incluye el período completo. En lo que llevamos de la década de los noventa no se ha registrado ningún año muy frío y dos fríos. Por lo tanto, hay un aumento claro de los años muy cálidos y cálidos a partir de los ochenta, pues de diecisiete años de la serie, once son cálidos y muy cálidos. Este ritmo alto se ve algo matizado en los años noventa, pues si bien aparecen cuatro años cálidos y muy cálidos, se dan dos fríos y uno templado. 
La desviación estándar anual en Pamplona para el total de la serie, años 1941-97, es 0,67. Para el período 1971-97 la anual es 0,57, o sea inferior con respecto a la del período anterior. Si nos fijamos en el periodo 1941-70 la desviación estándar anual de 0,75 es elevada y vuelve a parecerse a la de la serie total. Finalmente para los años 1981-97 la desviación estándar anual es de 0,56.

Al igual que ocurría en Santesteban, existe una diferencia entre los años 71-97 y 81-97 por una parte, con una desviación estándar inferior, y los años 1941-97 y 41-70 por otra, con una desviación estándar superior. Desde el comienzo de las series hasta el año setenta las variaciones, sin duda, fueron más acusadas. En general, los meses de invierno tienen valores más altos y los de verano más bajos. Enero es el mes más variable en todos los períodos y esta variabilidad se acentúa más a partir de los años ochenta. Destaca el mes de febrero por sus registros elevados en los años 1941-70. En estos mismos años la primavera tiene valores más elevados que el otoño.

El coeficiente de variación en Pamplona resulta más alto en los períodos 1941-97 y 1941-70 (5,4 y 6 respectivamente) que en los 1971-97 y $1981-97(4,6$ y 4,4). Los meses de invierno son los más variables en todos los períodos y los de verano los que menos variabilidad presentan. De los meses de primavera el más variable es marzo y de los de otoño, noviembre. Destaca la muy alta variación de enero en todos los períodos.

En definitiva se puede afirmar que durante el período 1941-70 se registró mayor variabilidad que en el resto de períodos. A partir de los años ochenta la variabilidad global es inferior. En estos últimos años los meses presentan, también, una fuerte variación, sobre todo enero. A los meses de invierno le siguen los de primavera y otoño.

En Carcastillo- la Oliva, para el periodo comprendido entre 1941-97 la temperatura media más alta fue de $14,8^{\circ}$ (año 1947) y la más baja de $11,8^{\circ}$ (años 1956 y 1980), por lo que el recorrido o rango es de $3^{\circ}$, inferior al del observatorio de Santesteban y ligeramente superior al de Pamplona.

Según los datos de los quintiles, en el período 1941 -97 se han contabilizado 14 años muy fríos, 11 fríos, 9 templados, 12 cálidos y 11 muy cálidos. En los años 41-70 se han observado 6 años muy fríos, 7 fríos, 7 templados, 5 cálidos y 5 muy cálidos. En el periodo $71-97$ se han visto 8 años fríos, 4 fríos, 2 templados, 7 cálidos y 6 muy cálidos. En los años 81-97 se han observado 1 año muy trío, 1 frío, 2 templados, 7 cálidos y 6 muy cálidos.

Estos resultados obtenidos en Carcastillo permiten apuntar unas primeras observaciones. De los once años muy cálidos que registra la serie, 
seis han tenido lugar a partir del año 1981, dos de los cuales pertenecen a los años noventa. Algo más de la mitad de los años cálidos anotados, o sea siete de doce, se dan a partir de 1981, y de ellos tres en los años noventa. En el extremo contrario se observa que sólo tiene lugar un año muy frío desde 1981 de los catorce registrados en toda la serie y un frío de los once que incluye el período completo. En lo que llevamos del noventa no se ha registrado ningún año muy frío y uno frío. Por lo tanto, hay un incremento claro de los años muy cálidos y cálidos a partir de los ochenta, pues de diecisiete años de la serie, trece son cálidos y muy cálidos, lo que supone más de las tres cuartas partes. Este ritmo alto se ve ligeramente suavizado en los años noventa.

La desviación estándar anual en Carcastillo para el total de la serie, años 1941-97, es 0,73. Para el período 1971-97 la anual es 0,69, o sea inferior con respecto a la del período anterior. Si nos fijamos en el período 1941-70 la desviación estándar anual de 0,76 es elevada y vuelve a parecerse a la de la serie total. Finalmente para los años 1981-97 la desviación estándar anual es de 0,54.

Por lo tanto, se puede afirmar que, al igual que ocurría en Santesteban y Pamplona, existe una diferencia entre los años 71-97 y 81-97 por una parte, con una desviación estándar inferior, y los años 1941-97 y 41-70 por otra, con una desviación estándar superior. Desde el comienzo de las series hasta el año setenta las variaciones, sin duda, fueron más acusadas. En general, los meses de invierno tienen valores más altos y los de verano más bajos en los períodos 1941-70 y 1941-97. Enero es el mes más variable en todos los períodos y esta variabilidad se acentúa más a partir de los años ochenta. Destaca el mes de febrero por sus registros elevados en los años 1941-70. A partir de los años ochenta septiembre y octubre son los meses de mayor dispersión, seguidos de enero y mayo; por el contrario, los meses de verano, marzo, abril, noviembre y diciembre tienen inferior desviación.

El coeficiente de variación en Carcastillo resulta más alto en los periodos $1941-97$ y $1941-70$ (5,5 y 5,7 respectivamente) que en los 1971-97 y 1981-97 (5,2 y 4). Los meses de invierno son los más variables en todos los períodos y los de verano los que menos variabilidad presentan. De los meses de primavera el más variable es marzo y de los de otoño, noviembre. Destaca la muy alta variación de enero en todos los períodos.

En definitiva se puede afirmar que durante el período 1941-70 se registró mayor variabilidad que en el resto de períodos. A partir de los años ochenta la variabilidad global es inferior. En estos últimos años los meses presentan, también, una fuerte variación, sobre todo enero. Últimamente está resultan- 
do muy variable el mes de octubre que se sitúa detrás de los de invierno. Le siguen en orden de mayor a menor marzo, noviembre, abril y mayo.

\section{FRECUENCIA Y PROBABILIDAD}

Las temperaturas medias anuales del observatorio de Santesteban se han agrupado en ocho clases, comenzando desde $12^{\circ}$ y terminando en $15,9^{\circ}$, con una longitud de intervalos de $0,5^{\circ}(3)$. De esta manera el mayor número de años se sitúa en los cuatro intervalos centrales y la temperatura media anual de toda la serie cae próxima al extremo final del intervalo central (Gráfico no 1).

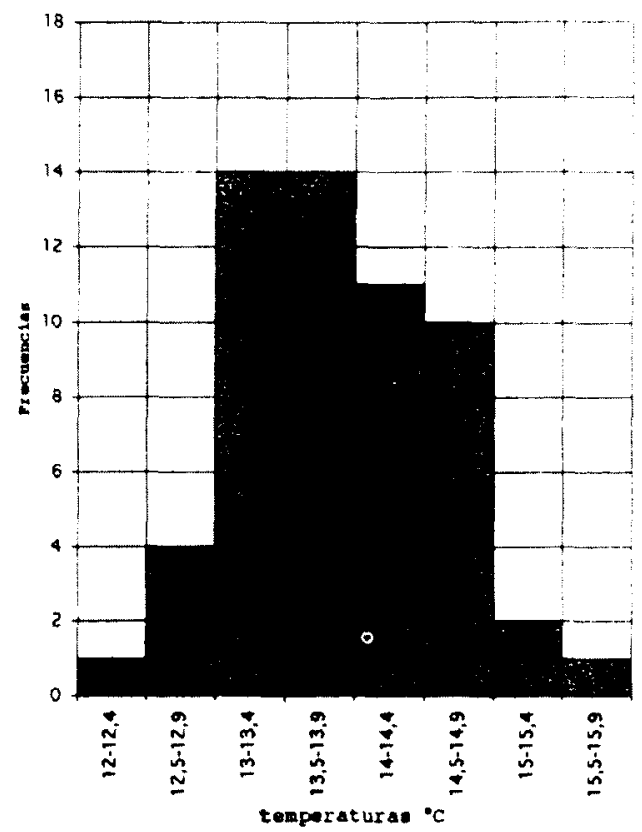

Gráfico 1. Santesteban. Histograma de frecuencias (1941-97).

En Pamplona se han agrupado en ocho clases, comenzando desde $10,9^{\circ}$ y terminando en $14^{\circ}$, con una longitud de intervalos de $0,4^{\circ}$. Así el mayor número de años se sitúa en tres intervalos centrales (3) y la temperatura media anual de toda la serie cae próxima al extremo final del intervalo central (Gráfico nº 2). 


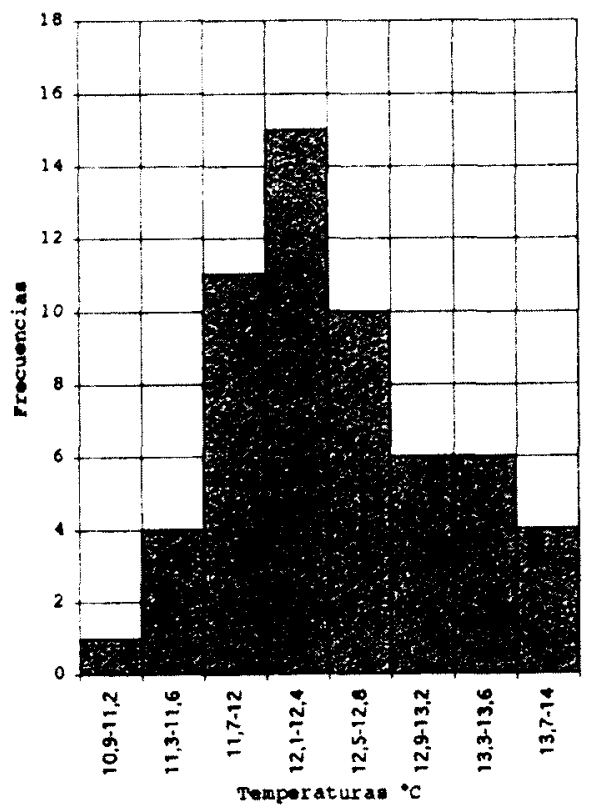

Gráfico 2. Pamplona. Histograma de frecuencias (1941-97).

En Carcastillo- la Oliva se han agrupado en ocho clases, comenzando desde $11,61^{\circ}$ y terminando en $15,20^{\circ}$, con una longitud de intervalos de $045^{\circ}$. Por lo tanto, el mayor número de años se sitúa en tres intervalos centrales (3) y la temperatura media anual de toda la serie cae próxima al extremo final del intervalo central (Gráfico $n^{\circ} 3$ )

Con estos agrupamientos la prueba de Kolmogorov-Lilliefors verifica la normalidad de la distribución poblacional de las temperaturas medias anuales calculada para los extremos superiores de cada una de las categorias establecidas. En Santesteban la máxima diferencia entre la distribución empírica y teórica es 0,0611 , en Pamplona 0,1030 y en Carcastillo 0,0307 . Si se comparan estos datos con el valor crítico $D(57 ; 0,05)$, calculado en función de los 57 años de la serie y el riesgo o nivel de significa-

3 En Santesteban, los rangos superiores y el número de años de cada intervalo son: $12,4^{\circ}(1)$; $12,9^{\circ}(4) ; 13,4^{\circ}(14) ; 13,9^{\circ}(14) ; 14,4^{\circ}(11) ; 14,9^{\circ}(10) ; 15,4^{\circ}(2) ;$ y $15,9^{\circ}(1)$. En Pamplona son: $11,2^{\circ}(1) ; 11,6^{\circ}(4) ; 12^{\circ}(11) ; 12,4^{\circ}(15) ; 12,8^{\circ}(10) ; 13,2^{\circ}(6) ; 13,6^{\circ}(6) ;$ y $14^{\circ}$. En Carcastillo son: $12,05^{\circ}(3) ; 12,50^{\circ}(6) ; 12,95^{\circ}(11) ; 13,40^{\circ}(14) ; 13,85^{\circ}(12) ; 14,30^{\circ}(5) ; 14,75^{\circ}(5) ; y 15,20^{\circ}$. 


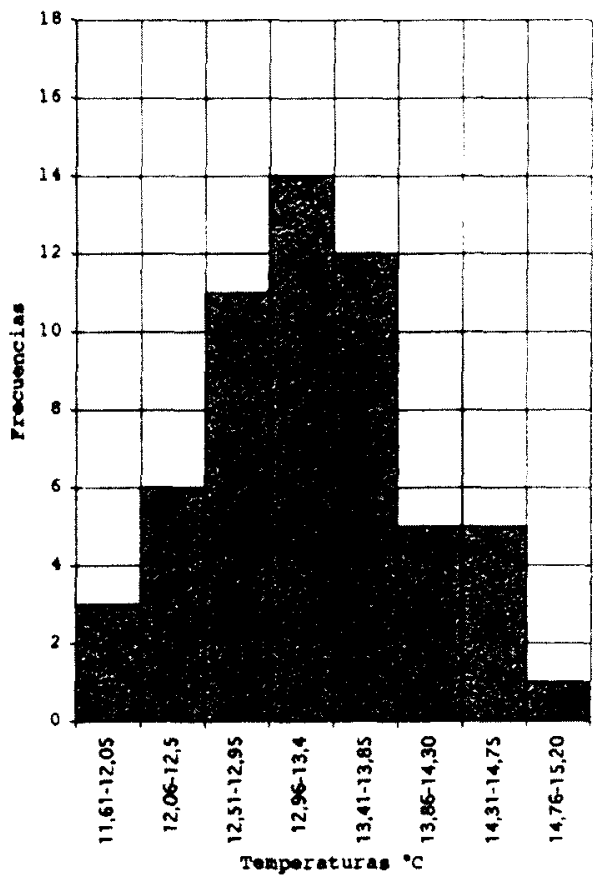

Gráfico 3. Carcastillo. Histograma de frecuencias (1941-97).

ción 0,05 , que arroja la cantidad de $0,1173(0,886 / \sqrt{ } 57)$ se observa que es netamente inferior y por lo tanto el ajuste es bueno ${ }^{4}$.

Por lo tanto, la distribución de frecuencias de las temperaturas medias anuales en los tres observatorios pueden ajustarse mediante una ley 0 distribución normal. Se acepta con un nivel de significación del $5 \%$ la bondad de su ajuste mediante la distribución normal. Dado el tamaño de la muestra y la potencia de la prueba es altamente probable que el ajuste sea bueno.

4 Se ha realizado para ello la prueba de Kolmogorov-Lilliefors (Raso, 1987) para la verificación de la normalidad de la distribución poblacional de las temperaturas medias anuales en los observatorios de Santesteban, Pamplona y Carcastillo. Se han calculado los valores de las funciones de distribución empirica $F e(X j)$ y teórica $F t(X j)$ para los extremos superiores de cada una de las categorías que se han establecido. La máxima diferencia entre las dos distribuciones $F e$ $(X j)$ - $F t(X j)$ se han calculado en función de los 57 años de la serie y el riesgo o nivel de significación 0,05 . Al ser los datos obtenidos en los observatorios nada se opone a aceptar la hipótesis nula Ho. 
El segundo coeficiente de sesgo de Pearson, que es de 0,6732 en Santesteban, indica que la distribución es simétrica, aunque presenta un débil sesgo positivo hacia la derecha, superior al de los otros dos observatorios. En Pamplona es de 0,4023, e indica que la distribución es más simétrica que en Santesteban, aunque presenta un escaso sesgo positivo hacia la derecha. En Carcastillo, la distribución es simétrica, con poco sesgo positivo hacia la derecha, inferior al de los otros dos observatorios ${ }^{5}$.

\section{ORGANIZACIÓN O ALEATORIEDAD DE LAS SERIES}

Después de observar las gráficas de temperaturas anuales en los tres observatorios, se ha procedido a comprobar, ante las dudas existentes, si las series son aleatorias, sin autocorrelación temporal, o si, por el contrario, están organizadas.

Por ello, y una vez vistas las gráficas de temperaturas medias anuales, se han dividido las series para su estudio en cuatro períodos: años 1941 a 1997; años 1941 a 1970; años 1971 a 1997; y años 1981 a 1997. Se ha aplicado el test de Von Neumann a las temperaturas medias anuales de los cuatro períodos señalados y a sus medias móviles de cinco años para comprobar su aleatoriedad $u$ organización ${ }^{6}$.

Las temperaturas medias anuales de las series completas para el período 1941-1997 muestran la existencia de una organización alta en Santesteban y Carcastillo y media en Pamplona (Santesteban 0,959; Pamplona 1,408; Carcastillo 1,056).

Las temperaturas medias anuales para el período 1971-1997 ponen de manifiesto la existencia de una organización alta en los tres observatorios

5 El segundo coeficiente de sesgo de Pearson es idóneo para ver el grado de simetria o asimetria de la curva, o si la curva presenta sesgo hacia la derecha o izquierda. Se calcula aplicando la fórmula: 3 (media-mediana)/desviación estandar. Si los valores se sitúan junto a 0 no hay asimetria, si son negativos hablariamos de sesgo a la izquierda y, en caso contrario, hacia la derecha.

El test de Von Neumann se utiliza para saber si la serie es aleatoria u organizada (Raso, 1967, pág. 228). Consiste en calcular el parámetro d2, según la siguiente fórmula:

$$
d^{2}=\frac{\sum_{i=1}\left(Y_{++1}-Y_{i}\right)^{2}}{N-1}
$$

Si la serie es aleatoria d2 es un valor cercano a dos veces la varianza y, si la serie está organizada, se alejará de dicha cifra. 
navarros (Santesteban 0,9009; Pamplona 1,066; Carcastillo 1,033). Para el período 1981-1997 demuestran que estamos ante una serie aleatoria, sin organización con resultados muy cercanos a dos en Santesteban y Carcastillo y algo organizada en Pamplona (Santesteban 1,931; Pamplona 1,474; Carcastillo 1,871). Finalmente, en los años 1941-1970, las temperaturas medias anuales muestran una serie claramente organizada en los observatorios de Santesteban y Carcastillo y con tendencia hacia la aleatoriedad en Pamplona (Santesteban 1,166; Pamplona 1,630; Carcastillo 1,097).

A la vista de los datos se puede señalar el carácter organizado de tres de los cuatro periodos elegidos: el total 1941-1997 y los períodos fragmentados: 1971-1997 y 1941-1970. En este último, sin embargo, el observatorio de Pamplona muestra tendencia aleatoria. El período 1981-1997 es aleatorio y no presenta organización sobre los totales anuales.

\section{GRADO DE CORRELACIÓN ENTRE LOS PERIODOS CONSIDERADOS Y LAS TEMPERATURAS MEDIAS}

El coeficiente de correlación de Pearson ${ }^{7}$ indica la relación funcional existente entre la variable aumento de temperaturas y los años para los diferentes períodos considerados y el de determinación $\left(R_{2}\right)$ el tanto por ciento de la varianza que se explica por la correlación.

En el período 1941-1997 no existe apenas correlación lineal, y los datos muestran una ligera correlación positiva en Pamplona y Carcastillo y escasa negativa en Santesteban (Santesteban -0,11; Pamplona 0,124; Carcastillo 0,02). Si los cálculos se hacen con respecto a las medias móviles de cinco años, la correlación sigue siendo muy baja y negativa en los tres observatorios considerados (Santesteban -0,29; Pamplona -0,06; Carcastillo -0,03).

Lo mismo sucede en el período 1941-1970. Carcastillo y Pamplona tienen una correlación baja y decreciente, y Santesteban ligeramente alta y creciente (Santesteban 0,111; Pamplona -0,130; Carcastillo-0,530). Si se

\footnotetext{
La correlacion puede ser positiva, cuando las dos variables crecen simultáneamente y negativa cuando una crece y otra disminuye. Los límites se sitúan entre -1 y +1 . Un valor absoluto elevado refleja una relación fuerte, mientras que al aproximarse a cero, indica que la relación se va disipando hasta llegar a la independencia de las dos variables, cuando es igual a 0 . El coeficiente de determinación es el cuadrado del coeficiente de correlacion lineal. Es la parte de la varizanza explicada (Grupo Chadule, pág. 158).
} 
tienen en cuenta las medias móviles de cinco años Santesteban presenta una débil correlación creciente, Pamplona decreciente y media y Carcastillo decreciente y ligeramente alta (Santesteban 0,212; Pamplona 0,530; Carcastillo -0,800). El coeficiente de determinación señala que en Carcastillo más de un sesenta por ciento de la varianza se explica por la correlación, mientras que en Pamplona tan solo un veintiocho por ciento.

Por el contrario, existe una correlación lineal fuerte y positiva en los últimos veintisiete años, período 1971 a 1997, cuyos coeficientes se alejan del cero y se sitúan próximos al 0,7 en los tres observatorios considerados (Santesteban 0,707; Pamplona 0,7; Carcastillo 0,642). Por lo tanto, hay una indicación clara del incremento de las temperaturas en estos años, corroborada todavía más si se tienen en cuenta los datos de las medias móviles de cinco años, que alcanzan una correlación muy alta, cercana o superior al 0,9 (Santesteban 0,897; Pamplona 0,933; Carcastillo 0,836). El coeficiente de determinación señala que en Carcastillo casi un setenta por ciento de la varianza se explica por la correlación, un ochenta por ciento en Santesteban y casi un noventa por ciento en Pamplona.

Para los últimos dieciséis años, período comprendido entre los años 1981-1997, el coeficiente vuelve a acercarse al cero y con ello a dar una correlación pequeña, de signo creciente, aunque mucho más nítida que en la serie total de datos. Pamplona tiene una correlación lineal media positiva próxima al 0,5 , mientras que en Santesteban y Carcastillo se reduce el coeficiente (Santesteban 0,228; Pamplona 0,537; Carcastillo 0,146). Al efectuar los cálculos sobre las medias móviles de cinco en cinco años el grado de correlación aumenta ampliamente en Pamplona, que supera el C,8 y los valores resultan bajos en Santesteban y Carcastillo (Santesteban 0,354; Pamplona 0,808; Carcastillo 0,21). El coeficiente de determinación señala que en Pamplona un sesenta y cinco por ciento de la varianza se explica por la correlación. En los otros dos observatorios los valores son muy bajos.

En definitiva, es el período 1971-1997, o sea los últimos veintisiete años, en que existe una clara correlación de signo creciente en los tres observatorios considerados, entre las temperaturas medias y los años. El hecho de que en el período 1981-1997 esto no resulte tan claro hace suponer que la tendencia al alza de los años setenta y ochenta posiblemente se haya visto aminorada en los años noventa. En el período largo, 1941-97, y en el 41-70, el grado de correlación es débil y en algunos observatorios negativo debido, sin duda, a una serie de años muy cálidos que tienen lugar en los cuarenta, y entre finales de los cincuenta y comienzos de los sesenta. 


\section{TENDENCIA FUTURA ANUAL}

Se ha efectuado el ajuste por el método de los mínimos cuadrados y el cálculo de la ecuación de la recta de regresión sobre los totales anuales y sobre las medias móviles de cinco años para ver a qué nivel aumentan o disminuyen las temperaturas anuales de los observatorios elegidos, conforme los años avanzan. Para cada observatorio, se hace primeramente un análisis rápido de toda la serie, período 1941-97, con los diferentes ciclos y el comentario de la tendencia lineal sobre el total ${ }^{8}$ y las medias móviles de cinco años ${ }^{9}$. Posteriormente se estudian los resultados de los tres periodos en los que se ha fraccionado la serie.

En el observatorio de Santesteban, teniendo en cuenta el total de la serie, período 1941-97, se observa la presencia de dos ciclos con temperaturas medias anuales elevadas que van a ser las más altas de la serie, años 194349 y 1956-66; y dos con temperaturas bajas, 1950-55 y 1967-80 (Gráfico $n^{\circ}$ 4). Después del período descendente 1960-71 se inicia otro ascendente hasta nuestros días, con bastantes oscilaciones. El ritmo de crecimiento iniciado a partir del ochenta no sigue un ritmo tan alto en los noventa.

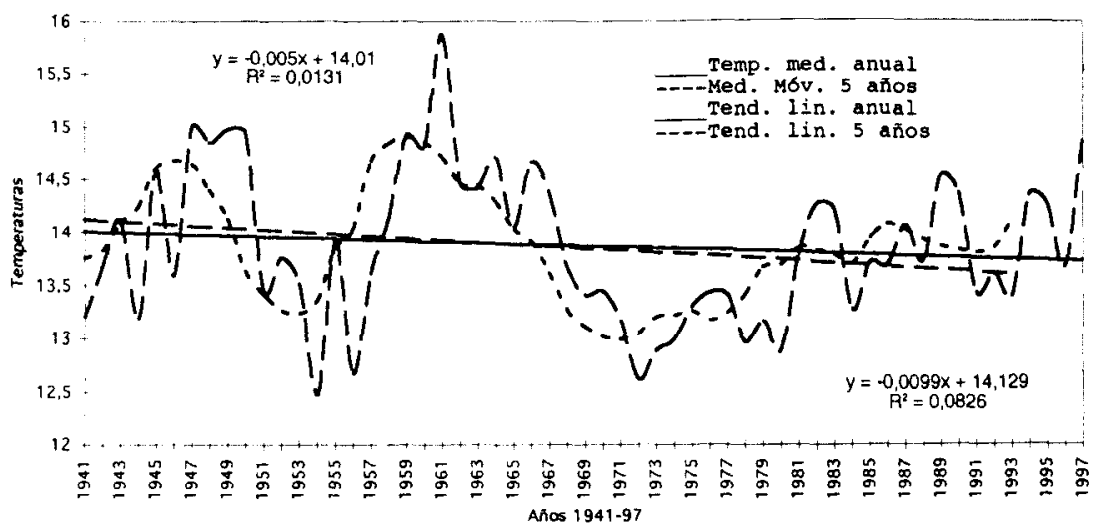

Gráfico 4. Santesteban. Temperaturas medias anuales, medias móviles 5 años y tendencia lineal (1941-97).

- Se trata de la obtención de la línea recta ideal hacia la cual tiende la nube de puntos de un diagrama de dispersión, la formula $Y=b X+a$. El problema consiste en calcular los parámetros $b$, coeficiente de regresion de $Y$ sobre $X$, que expresa la pendiente de la recta o valor que aumenta o disminuye. Esto permite ver cómo la temperaturas medias anuales van a evolucionar en un futuro próximo, en función de los años.

Se han calculado las medias móviles de cinco para suavizar las series, ver los distintos períodos existentes con mayor claridad y observar si existen algunas tendencias enmascaradas. 
Con estos resultados y considerando el total de la serie la tendencia resulta ligeramente negativa y se produce una disminución media anual de $0,005^{\circ}$ a partir de $14,01^{\circ}$. Si se obtiene la tendencia con las medias móviles de cinco años se produce un descenso medio anual de $0,0099^{\circ}$ a partir de $14,129^{\circ}$. Todo esto, como se ha afirmado anteriormente, con un coeficiente de correlación muy bajo, que no llega a explicar el diez por ciento de la varianza.

La presencia de temperaturas sumamente altas en los primeros períodos de la serie y las temperaturas bajas del largo período 1967-80, hace que la serie se inicie desde unos parámetros altos y que la tendencia sea decreciente.

En el período 1941-70 se observa con mayor detenimiento la presencia de los dos ciclos con temperaturas medias elevadas que van a ser las más altas de la serie, años 1943-49 y 1956-66 y dos con temperaturas bajas, 1950-55 y 1967-70 Termina este período con un tramo descendente desde 1960.

Con estos resultados la tendencia resulta ligeramente positiva y se produce un incremento medio anual de $0,0098^{\circ}$ a partir de $13,929^{\circ}$. Si se obtiene la tendencia con las medias móviles de cinco años se produce un incremento medio anual de $0,0142^{\circ}$ a partir de $13,971^{\circ}$. Todo esto con un coeficiente de correlación muy bajo, que no llega a explicar el cinco por ciento de la varianza. La presencia de temperaturas sumamente altas en los primeros años de la serie hace que se inicie desde unos parámetros altos y que la tendencia sea tan sólo ligeramente creciente.

El período 71-97 en Santesteban parte de un año base muy bajo que marca el descenso amplio de los años anteriores (Gráfico $n^{\circ} 5$ ). Se inicia un ciclo ascendente o creciente de las temperaturas medias anuales, pero oscilante, con subidas y bajadas, que va durar hasta nuestros días. El ritmo de crecimiento iniciado a partir de los setenta, sigue su curso en los ochenta y da la sensación de que se ralentiza en los noventa, años en los que el crecimiento no es tan alto, como el esperado.

Con estos resultados y dado que en este período no entran los ciclos de altas temperaturas de los años cuarenta y cincuenta, la tendencia resulta creciente y se produce un aumento medio anual de $0,0515^{\circ}$ a partir

\footnotetext{
Se trata de aminorar los ciclos con el fin de dísminuir su influencia en la tendencia general y eliminar las pequeñas fluctuaciones que dificultan la observación de la tendencia. Esto supone perder información en los primeros y últimos años de la serie. Esto ha permitido fraccionar las series en los períodos que se han venido trabajando.
} 


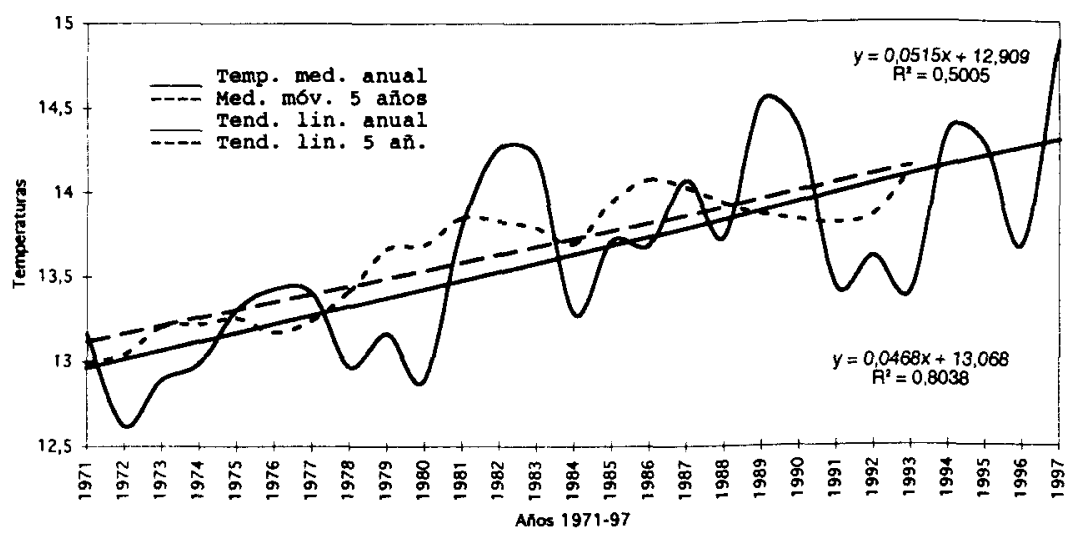

Gráfico 5. Santesteban. Temperaturas medias anuales, medias móviles de 5 años y tendencia lineal (1971-97)

de $12,909^{\circ}$. Si se obtiene la tendencia con las medias móviles de cinco años se produce un aumento medio anual de $0,0468^{\circ}$ a partir de $13,068^{\circ}$. Todo esto, a diferencia de los períodos anteriores, con un coeficiente de correlación muy alto $(0,707$ para los datos anuales y 0,897 para las medias móviles de cinco años), que explica el ochenta por ciento de la varianza, si se tienen en cuenta las medias móviles. Por lo tanto, el período 1971-97 presenta una clara tendencia creciente, con un incremento de las temperaturas significativo que dura hasta nuestros dias.

El período 81-97 presenta una tendencia creciente con oscilaciones. Se suceden los años cálidos, dominantes, pero en el medio se sitúan años más fríos. Se produce un aumento medio anual de $0,0203^{\circ}$ a partir de $13,771^{\circ}$. Si se obtiene la tendencia con las medias móviles de cinco años se produce un aumento medio anual de $0,011^{\circ}$ a partir de $13,816^{\circ}$. Todo esto con un coeficiente de correlación bajo $(0,228$ para los datos anuales y 0,354 para las medias móviles de cinco años), que explica un porcentaje bajo de la varianza. Por lo tanto, el período 1981-97 presenta una tendencia creciente, a un ritmo inferior al del período 71-97, con un incremento de la temperatura que dura hasta nuestros días. Sin embargo, conviene advertir que en estos últimos años los ciclos de temperaturas altas son inferiores a los de los años cuarenta y cincuenta, del comienzo de la serie global.

En el observatorio de Pamplona teniendo en cuenta el total de la serie, período 1941-97, se observa la presencia de dos ciclos con temperaturas medias anuales elevadas que van a ser las más altas de la serie, años 
1943-48 y 1951-60 y uno con temperaturas bajas, 1963-80 (Gráfico $n^{\circ} 6$ ) Después del período descendente 1957-63 se inicia otro ascendente y oscilante hasta nuestros días. El ritmo de crecimiento iniciado a partir del ochenta sigue siendo alto en los noventa. Las temperaturas elevadas de los últimos años tienden a asemejarse a las de los años cuarenta y cincuenta, sin alcanzarlas por poco.

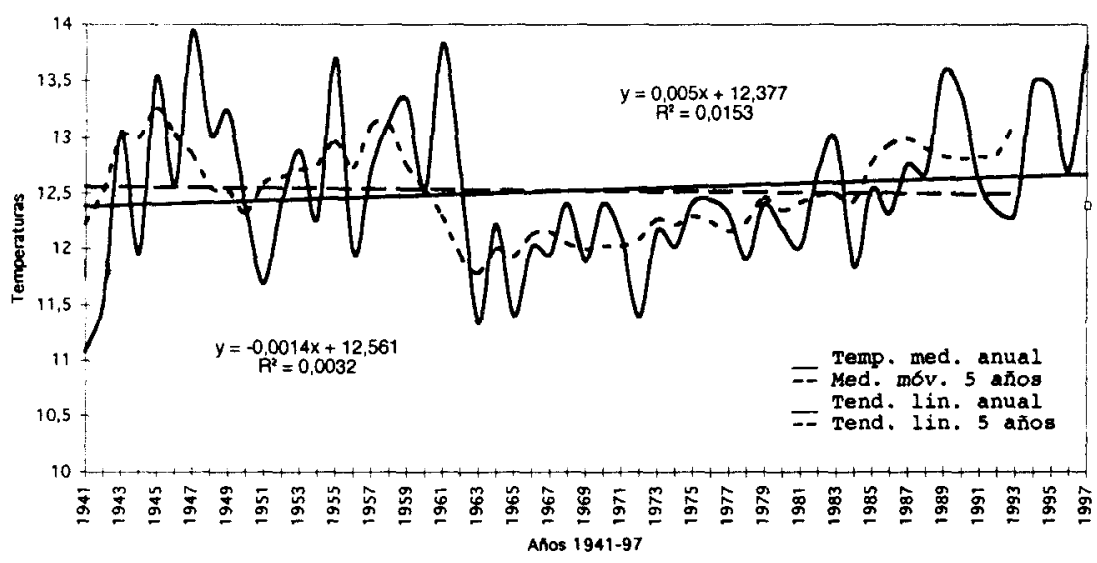

Gráfico 6. Pamplona. Temperaturas medias anuales, medias móviles de 5 años y tendencia lineal (1941-97)

Con estos resultados y cogiendo el total de la serie la tendencia resulta ligeramente positiva y se produce una aumento medio anual de $0,005^{\circ}$ a partir de $12,377^{\circ}$. Si se obtiene la tendencia con las medias móviles de cinco años se produce un ligero descenso medio anual de $0,0014^{\circ}$ a partir de $12,561^{\circ}$. Todo esto, como se ha afirmado con anterioridad, con un coeficiente de correlación muy bajo.

La presencia de temperaturas sumamente altas en los primeros años de la serie y las temperaturas bajas del largo período 1967-80, hace que la serie se inicie desde unos parámetros altos y que la tendencia sea ligeramente creciente, por lo que puede oscurecer lo que realmente está ocurriendo en los últimos años, aunque algo menos que en Santesteban.

El período 1941-70 se inicia con un año base bastante bajo y termina con unos años de incremento, pero dentro de un ciclo fluctuante de temperaturas medias. Se observa la presencia de los dos ciclos con temperaturas medias elevadas que van a ser las más altas de la serie, años 194348 y 1951-60 y uno con temperaturas bajas, 1963-70. A partir del año 
1963 comienza tímidamente el crecimiento, pero desde unos parámetros bajos.

Con estos resultados la tendencia resulta negativa y se produce una disminución media anual de $0,0115^{\circ}$ a partir de $12,68^{\circ}$. Si se obtiene la tendencia con las medias móviles de cinco años se produce una disminución media anual de $0,0285^{\circ}$ a partir de $12,97^{\circ}$. Todo esto con un coeficiente de correlación medio, que explica el veinticinco por ciento de la varianza si se tiene en cuenta las medias móviles de cinco años. La presencia de temperaturas sumamente altas en los primeros años de la serie hace que se inicie desde unos parámetros altos y que la tendencia sea decreciente.

El período 71-97 en Pamplona parte de un año base bajo que prosigue con el débil incremento iniciado a partir del año 1963 (Gráfico $n^{\circ}$ 7). Asi pues, continúa el ciclo ascendente o creciente de las temperaturas medias anuales, pero oscilante, que va durar hasta nuestros días. El ritmo de crecimiento iniciado a partir de los setenta, sigue su curso en los ochenta y en los noventa, años en los que el crecimiento es alto, sin llegar por poco a los años muy cálidos de comienzo de la serie.

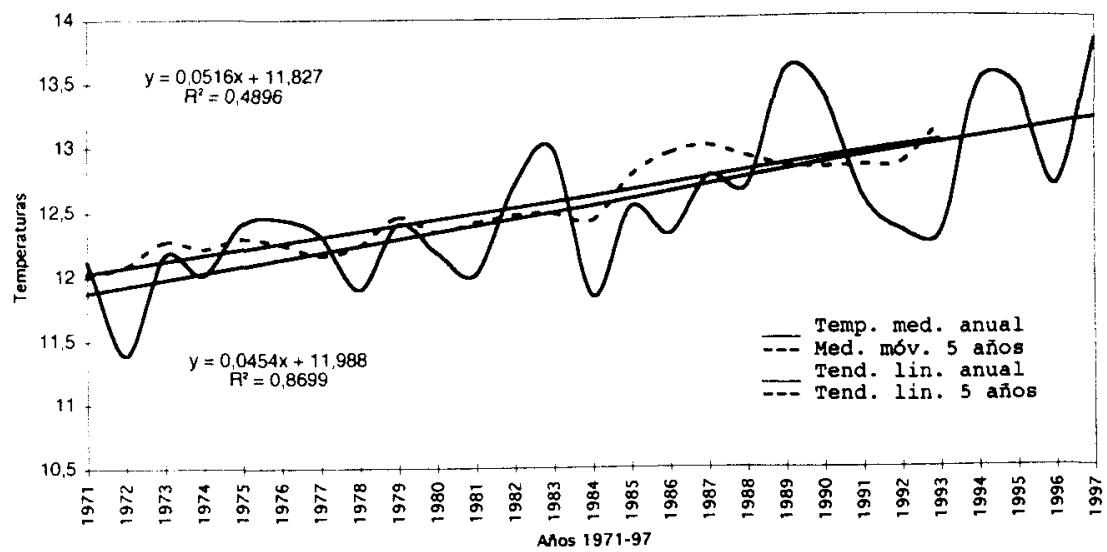

Gráfico 7. Pamplona. Temperaturas medias anuales, medias móviles de 5 años y tendencia lineal (1941-97)

Con estos resultados y dado que en este período no entran los ciclos de altas temperaturas de los años cuarenta y cincuenta, la tendencia resulta creciente y se produce un aumento medio anual de $0,0516^{\circ}$ a partir de $11,827^{\circ}$. Si se obtiene la tendencia con las medias móviles de cinco 
años se produce un aumento medio anual de $0,0454^{\circ}$ a partir de $11,988^{\circ}$. Todo esto, a diferencia de los períodos anteriores, con un coeficiente de correlación muy alto $(0,700$ para los datos anuales y 0,933 para las medias móviles de cinco años), que explica más del ochenta y cinco por ciento de la varianza, si tenemos en cuenta las medias móviles. Por lo tanto, el período 1971-97 presenta una clara tendencia creciente, con un incremento de la temperatura significativo que dura hasta nuestros días.

El período 81-97 presenta una tendencia creciente con osciliaciones. Se suceden los años cálidos, dominantes, pero entre medio se sitúan años más moderados. Se produce un aumento medio anual de $0,061^{\circ}$ a partir de $12,243^{\circ}$. Si se obtiene la tendencia con las medias móviles de cinco años se produce un aumento medio anual de $0,0491^{\circ}$ a partir de $12,419^{\circ}$. Todo esto con un coeficiente de correlación importante $(0,537$ para los datos anuales y 0,808 para las medias móviles de cinco años), que explica un porcentaje de dos tercios de la varianza si se efectúa sobre las medias móviles. Por lo tanto, el período 1981-97 presenta una tendencia creciente, a un ritmo semejante al del período 71-97, con un incremento de la temperatura que dura hasta nuestros días. Los ciclos de temperaturas altas se acercan a los de los años cuarenta y cincuenta, del comienzo de la serie global.

En el observatorio de Carcastillo teniendo en cuenta el total de la serie, período 1941-97, se observa la presencia de dos ciclos con temperaturas medias anuales elevadas que van a ser las más altas de la serie, años 1942-49 y 1981-97 y uno intermedio largo con temperaturas bajas, 195080 , con oscilaciones que rara vez superan la media del total de la serie (Gráfico $n^{\circ} 8$ ). El ritmo de crecimiento iniciado a partir del ochenta es alto en los noventa, aunque con algunas oscilaciones que, en casi todos los casos, se sitúan por encima de la media. Las temperaturas elevadas de los últimos años tienden a asemejarse a las de los años cuarenta y cincuenta, sin alcanzarlas por poco.

Con estos resultados y cogiendo el total de la serie la tendencia resulta ligeramente positiva y se produce una aumento medio anual de $0,0009^{\circ}$ a partir de $13,219^{\circ}$. Si se obtiene la tendencia con las medias móviles de cinco años se produce un ligero descenso medio anual de $0,012^{\circ}$ a partir de $13,267^{\circ}$. Todo esto, como se ha afirmado con anterioridad, con un coeficiente de correlación muy bajo.

La presencia de temperaturas sumamente altas en los primeros años de la serie y las temperaturas bajas del largo período intermedio, hace que la serie se inicie desde unos parámetros altos y que la tendencia sea ligeramente creciente para las temperaturas medias anuales y decrecien- 


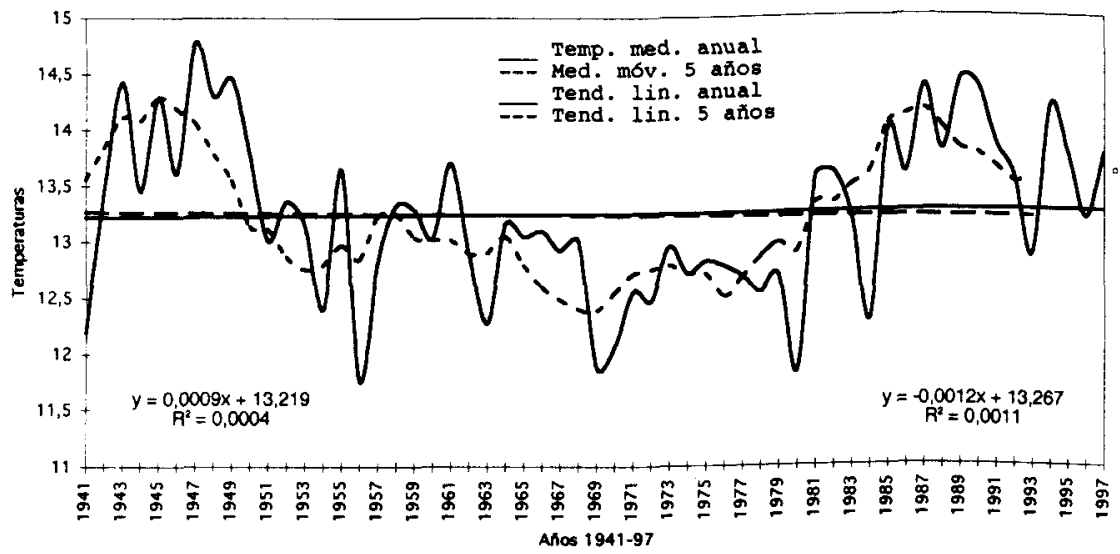

Gráfico 8. Carcastillo. Temperaturas medias anuales, medias móviles de 5 años y tendencia lineal (1941-97)

te para las medias móviles de cinco años, por lo que puede oscurecer lo que realmente está ocurriendo en los últimos años, aunque algo menos que en Santesteban y en Pamplona.

El período 1941-70 se inicia con un año base bastante bajo y después de un período alto, hasta 1949, en el que se obtienen los registros más elevados de la serie, los resultados descienden hasta los años setenta. El período termina con temperaturas medias muy bajas. En este ciclo intermedio de temperaturas débiles, sólo tres años superan la temperatura media 1941-97. Hay oscilaciones dentro del común denominador de temperaturas bajas.

Con estos resultados la tendencia resulta decreciente y se produce una disminución media anual de $0,0463^{\circ}$ a partir de $13,934^{\circ}$. Si se obtiene la tendencia con las medias móviles de cinco años se produce una disminución media anual de $0,0545^{\circ}$ a partir de $14,03^{\circ}$. Todo esto con un coeficiente de correlación medio-alto, que explica más del sesenta por ciento de la varianza, si se tiene en cuenta las medias móviles de cinco años. La presencia de temperaturas sumamente altas en los primeros años de la serie hace que se inicie desde unos parámetros altos y que la tendencia sea decreciente.

El período 71-97 en Carcastillo parte de un año base bajo que prosigue con el débil incremento iniciado a partir del año 1969 (Gráfico $n^{\circ}$ 9). Se trata de un ciclo ascendente o creciente de las temperaturas medias anuales, pero oscilante, con subidas y bajadas, a veces muy pronunciadas, que va durar hasta nuestros días. El ritmo de crecimiento iniciado a partir 


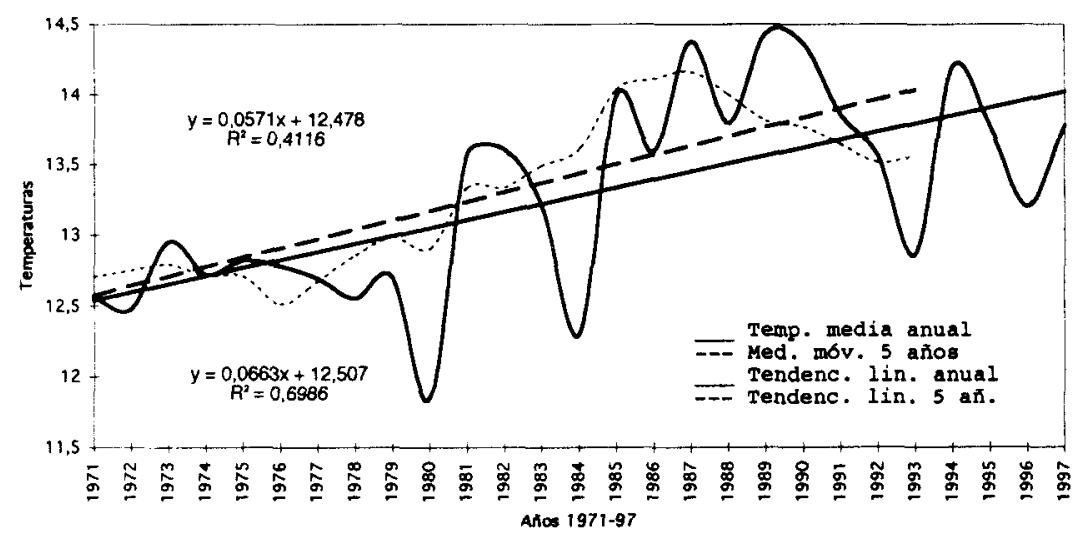

Gráfico 9. Carcastillo. Temperaturas medias anuales, medias móviles de 5 años y tendencia lineal (1941-97)

de los setenta, sigue su curso en los ochenta y en los noventa, años en los que el crecimiento es alto, sin llegar, por poco, a los años muy cálidos de comienzo de la serie.

Con estos resultados y dado que en este período no entran los ciclos de altas temperaturas de los años cuarenta y cincuenta, la tendencia resulta creciente y se produce un aumento medio anual de $0,0571^{\circ}$ a partir de $12,478^{\circ}$. Si se obtiene la tendencia con las medias móviles de cinco años se produce un aumento medio anual de $0,0663^{\circ}$ a partir de $12,507^{\circ}$. Todo esto, a diferencia de los periodos anteriores, con un coeficiente de correlación muy alto $(0,642$ para los datos anuales y 0,836 para las medias móviles de cinco años), que explica casi el setenta por ciento de la varianza, si tenemos en cuenta las medias móviles. Por lo tanto, el período 1971-97 presenta una clara tendencia creciente, con un incremento de la temperatura significativo que dura hasta nuestros días.

El período 81-97 presenta una tendencia creciente con osciliaciones. Se suceden los años muy cálidos, dominantes, y sólo dos años más moderados. Se produce un aumento medio anual de $0,0161^{\circ}$ a partir de $13,526^{\circ}$. Si se obtiene la tendencia con las medias móviles de cinco años se produce un aumento medio anual de $0,0153^{\circ}$ a partir de $13,613^{\circ}$. Por lo tanto, el período 1981-97 presenta una tendencia creciente, a un ritmo semejante al del período 71-97, con un incremento de la temperatura que dura hasta nuestros días. Los ciclos de temperaturas altas se acercan a los de los años cuarenta y cincuenta, del comienzo de la serie global, más aquí que en los dos observatorios anteriores. 


\section{INCREMENTO ESTACIONAL}

Una vez calculada la tendencia anual se ha procedido a un estudio estacional, estudiando la regresión lineal de laas cuatro estaciones del año, sólo para el período 1971-97, que es el más significativo, con el objeto de ver cúales son las estaciones del año que más y menos incremento de las temperaturas están registrando.

La tendencia resulta creciente en los tres observatorios en las cuatro estaciones del año (Gráfios 10, 11 y 12). La primavera es la estación del año que registra un aumento medio anual más importante en Pamplona y Carcastillo, muy por encima de la media anual (Pamplona $0,0787^{\circ}$ a partir de $9,8949^{\circ}$; Carcastillo $0,0955^{\circ}$ a partir de $10,643^{\circ}$ ) En cambio, en Santesteban, observatorio situado dentro del dominio oceánico, la primavera se incrementa un poco más que la media anual (Santesteban $0,0597^{\circ}$ a partir de $11,394^{\circ}$ ). Todo esto con un coeficiente de correlación superior al 0,6 (Pamplona 0,7249; Carcastillo 0,7646; Santesteban 0,6210).

La estación invernal registra un aumento medio anual más alto en Santesteban muy por encima de la media anual (Santesteban $0,064^{\circ}$ a partir de $7,0416^{\circ}$ ) En cambio, en Pamplona y Carcastillo, observatorios situados dentro de los dominios de transición y mediterráneo respectivamente, el invierno se incrementa menos que la media anual, y en Pamplona es la estación que menos crece (Pamplona $0,034^{\circ}$ a partir de 5,6123; Carcastillo $0,0517^{\circ}$ a partir de $5,3356^{\circ}$ ). Todo esto con un coeficiente de correlación que alcanza el 0,5 en Santesteban y Carecastillo (Pamplona 0,3581; Carcastillo 0,5703; Santesteban 0,6284).

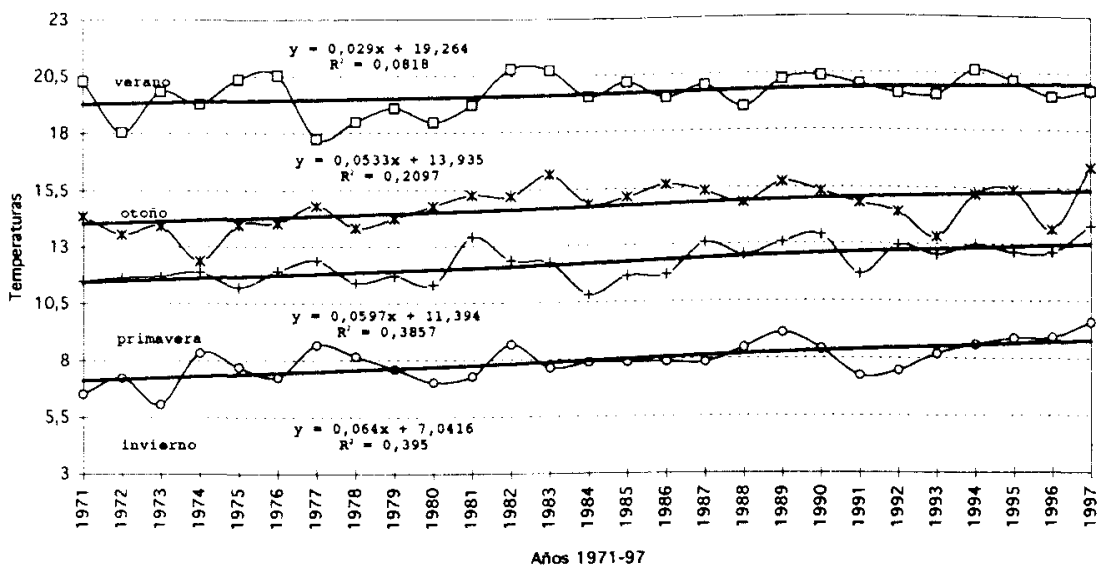

Gráfico 10. Santesteban. Temperaturas medias estacionales y tendencia lineal (1941-97) 


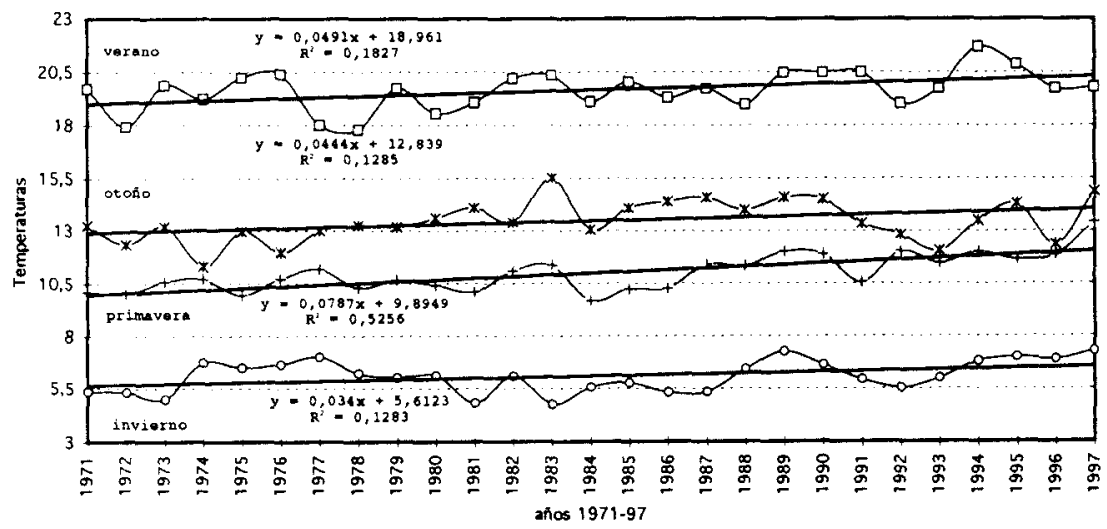

Gráfico 11. Pamplona. Temperaturas medias estacionales y tendencia lineal (1941-97)

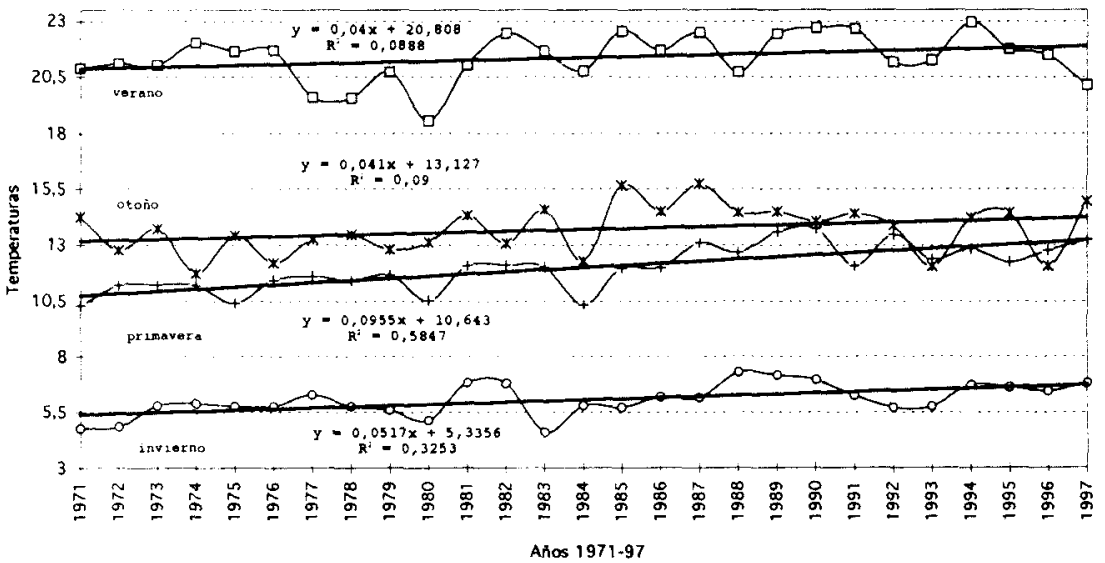

Gráfico 12. Carcastillo. Temperaturas medias estacionales y tendencia lineal (1941-97)

La estación estival registra un aumento medio anual menos importante por debajo de la media anual (Pamplona $0,0491^{\circ}$ a partir de $18,961^{\circ}$; Carcastillo $0,04^{\circ}$ a partir de $20,808^{\circ}$ ) En cambio, en Santesteban el incremento es mucho menor y es con mucho la estación del año que menor aumento de temperaturas registra( Santesteban $0,029^{\circ}$ a partir de $19,264^{\circ}$ ). Todo esto con un coeficiente bajo en los tres observatorios (Pamplona 0,4274; Carcastillo 0,2979; Santesteban 0,2860).

El otoño registra un aumento medio anual próximo a la media anual en Santesteban (Santesteban $0,0533^{\circ}$ a partir de $13,935^{\circ}$ ) y más bajo en 
Pamplona y Carcastillo (Pamplona $0,03444^{\circ}$ a partir de12,839 ; Carcastillo $0,041^{\circ}$ a partir de $13,127^{\circ}$ ). Todo esto con un coeficiente de correlación que sólo alcanza el 0,5 en Santesteban (Pamplona 0,3584; Carcastillo 0,3000 ; Santesteban 0,4579).

Por lo tanto, primavera sería la estación que está registrando un mayor incremento de las temperaturas desde el año 1971 hasta la actualidad en Carcastillo y Pamplona, observatorios con clima mediterráneo continental y transición oceánico-mediterráeno e invierno en Santesteban, de marcada tendencia oceánica. Los veranos registran aumentos más débiles, sobre todo en Santesteban. Finalmente el otoño tiene un incrfemento inferior a la media en todosx los observatorios (Gráficos 10, 11 y 12).

\section{CONCLUSIONES}

Las series CRONOLÓGICAS de temperaturas medias desde el año 1941 hasta 1997 en los observatorios de Santesteban, Pamplona y Carcastillo-la Oliva señalan las características y la evolución termométrica en los últimos años y la tendencia futura, con todas las reservas lógicas con las que hay que admitir los datos en este tipo de trabajos estadísticos descriptivos.

1. Los años más cálidos de las series no tienen lugar en los últimos años, sino en las décadas de los cuarenta, cincuenta y sesenta. A partir de 1981 hay un aumento importante de la temperatura media y de la mediana con respecto al total de la serie y a los otros períodos en Pamplona y Carcastillo, y ligero en Santesteban. Desde este año se nota una escasa presencia de años fríos y una frecuencia importante de años cálidos, que en el observatorio de Carcastillo- la Oliva llegan a asemejarse a las primeras décadas cálidas. Por lo tanto, hay un incremento de los años muy cálidos y cálidos a partir de los ochenta. Este ritmo ascendente de los ochenta se ve ligeramente suavizado en los años noventa, más visible en Pamplona y Santesteban, en donde se observan dos y tres años fríos respectivamente.

2. En cuanto a la variación, existe una diferencia entre los años 71-97 y 81-97 por una parte, con una desviación estándar inferior, y los años 1941-97 y 41-70 por otra, con una desviación estándar superior. Desde el comienzo de las series hasta el año setenta las variaciones, sin duda, fueron más acusadas.

3. En el período 1971-1997,existe una clara correlación de signo creciente en los tres observatorios considerados. El hecho de que en el período 1981-1997 esto no resulte tan claro hace suponer que la tendencia al alza de los años setenta y ochenta posiblemente se haya visto suavizada 
en los años noventa. En el período largo, 1941-97, y en el 41-70, el grado de correlación es débil y en algunos observatorios negativo debido, sin duda, a una serie de años muy cálidos que tienen lugar en las décadas de los cuarenta, cincuenta y sesenta.

4. Si se tiene en cuenta el total de la serie, período 1941-97, se observa la presencia de tres momentos distintos. El primero de ellos, cálido, ocupa la primera década en Santesteban (años cuarenta) y las dos primeras en Pamplona y Carcastillo (años cuarenta y cincuenta). El segundo, frío, con tendencia creciente llega hasta los ochenta y es más largo en Santesteban. Y el tercero, cálido, con un ritmo de crecimiento alto se inicia a partir del ochenta y se suaviza en los noventa, con temperaturas elevadas de los últimos años que tienden a asemejarse a las de los años cuarenta y cincuenta, sobre todo en Carcastillo.

La presencia de temperaturas sumamente altas en los primeros años y las temperaturas bajas del largo período posterior, hace que la serie se inicie desde unos parámetros altos y que la tendencia sea ligeramente creciente o decreciente en los tres observatorios, tanto con las medias anuales como con las medias móviles de cinco años, y con un coeficiente de correlación muy bajo.

El período 71-97, por el contrario, es altamente significativo y presenta una clara tendencia creciente en los tres observatorios con un alto grado de correlación. El período 81-97 presenta también una tendencia creciente con osciliaciones y con un coeficiente de correlación bajo. Se suceden los años cálidos dominantes, pero en medio se sitúan años más moderados. Este periodo presenta una tendencia creciente, con un incremento de la temperatura que dura hasta nuestros días. Los ciclos de temperaturas altas se acercan a los de los años cuarenta y cincuenta, del comienzo de la serie global, más en Carcastillo que en los dos observatorios anteriores.

5. En cuanto a la tendencia estacional en los últimos treinta años, la primavera es la estación que está registrando un mayor incremento de las temperaturas en Carcastillo y Pamplona, observatorios con clima mediterráneo continental y transición oceánico-mediterráneo, e invierno en Santesteban, observatorio de marcada tendencia oceánica. Los veranos registran incrementos más débiles, sobre todo en Santesteban. Finalmente el otoño tiene un incremento inferior a la media en todos los observatorios.

\section{BIBLIOGRAFÍA}

Arley, R., Grisollet, H. y Guilmet, B. (1973): Climatologie. Méthodes et pratiques, Paris, Gauthiers-Villards. 
Cuadrat Prats, J.M. (1989): “Las oscilaciones recientes en Zaragoza (1865-1984)". Geographicalia, págs. 53-60.

BOUCHER, A. (1977): "Longues séries de mesures de la témperature aux observatories de Toulouse, pic de Midi, Bordeaux Floriac et Toulouse». La Météorologie, VI, 8, págs. 213 219.

Fernandez Garcia, F. (1994): “Los cambios climáticos recientes. Tendencias metodológicas y estado de la cuestión en España peninsular», en Cambios y variaciones climáticas en España, Actas de la Y Reunión del grupo de Climatología de la A.G.E. págs. 19-33.

Fernandez García, F. (1995): Manual de climatología aplicada, Madrid, Sintesis.

FONT Tultot, I. (1988) : Historia del clima de España, cambios climáticos y sus causas, Madrid, I.N.M., 298 págs.

Galán, E. y Fernandez, F. (1992): "Metodología del análisis temporal y espacial de los elementos climáticos". $\vee$ Coloquio de Geografía cuantitativa, págs. 437-451, Universidad de Zaragoza, Asociación de Geógrafos Españoles.

Garcia legaz, C. y Martinez Molina, I. (1984): Pruebas de significación en climatología. Madrid, Instituto Nacional de Meteorología, A-87.

GRUPO CHADULE (1980): Iniciación a los métodos estadísticos en Geografía, Barcelona, Ariel.

Martin Vide, J. y MoReno Garcia, Ma.C. (1994): "Algunos indicadores no usuales en el estudio del cambio climático". En Cambios y variaciones climáticas en España, Actas de la $\checkmark$ Reunión del grupo de Climatología de la A.G.E. págs. 65-72.

Pegur, CH. (1961): Précis de climatologie, Paris, Masson.

Pejenaute Goñi, J. (1990) : Tipos de tiempo y clima de las Comarcas Navarras (tesis de doctorado), Pamplona Gobierno de Navarra, Príncipe de Viana.

Pejenaute Goñi, J.M. (1992) : El clima de Navarra, Pamplona, Ediciones Eunate, 223 págs.

Quereda SalA, J. y Montón Chiva, E. (1994): "Calentamiento significativo en el Mediterráneo español», en Cambios y variaciones climáticas en España, Actas de la Y Reunión del grupo de Climatología de la A.G.E. págs. 347-360.

RASO, J.M. (1987): "Variaciones recientes de la temperatura media en el observatorio del Ebro». Madrid, Anales Universidad Complutense, 7, págs. 155-165.

RASO, J.M. (1994): "Evolución reciente de las temperaturas medias anuales en España". Barcelona, Avances en climatología histórica en España. Barcelona, Oikos-tau, De. Javier Martín Vide, págs. 91-123.

Raso, J.M.; Martín VIDE, J. y Clavero, P. (1987): Estadística básica para Ciencias Sociales. Barcelona, Ariel. 